\title{
ANALYSES OF TANNINS IN REGIONAL SPECIFIC CEYLON TEAS
}

\author{
By \\ N.L.W.S.A. Karunaratne \\ GS / MSC / FOOD / 2799 / 06
}

Thesis is submitted to the University of Sri Jayewardenepura as the partial fulfillment requirement for the award of

The degree of Masters of Science

In

Food Science and Technology

Department of Food Science \& Technology

Faculty of Applied Sciences

University of Sri Jayewardenepura 


\title{
Dedicated to
}

My ever loving late father,

My most Precious Mother

Who nurtured and groomed me

To be a Valued Citizen.

\author{
Also to \\ My loving wife \\ \& \\ Little daughter
}




\section{DECLARATION}

I do hereby declare that the work described in this thesis was carried out by me under the supervision of Dr. K.K.D.S. Ranaweera and Mr. Chaminda Munasinghe and a report on this has not been submitted in whole or in part to any University or any other institution for another Degree/diploma.

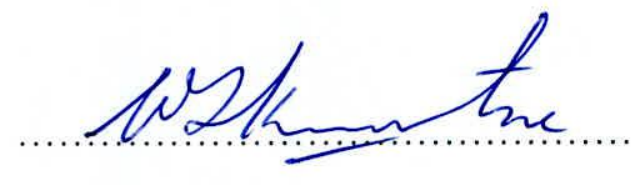

$14-03-2009$
N.L.W.S.A.Karunaratne

Date

Certified by:

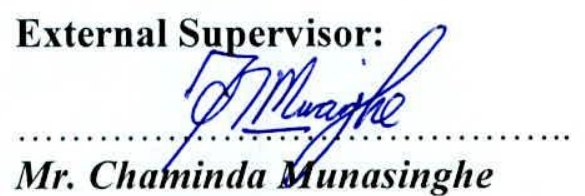

Laboratory Manager,

Unilever Sri Lanka Ltd.,

258, .Vincent Perera Mawatha,

Colombo 14.

\section{Internal Suppervisor:}

Dr. K.K.D.S. Ranaweera,

Co-ordinator of Msc. in Food Science \& Technology

Head Department of Food Science \& Technology

University of Sri Jayewardenepura 


\section{TABLE OF CONTENT}

Acknowledgement

Page No.

Abstract

05

Chapter 01

$\begin{array}{ll}\text { 1- Introduction } & 09\end{array}$

1.1History of tea $\quad 09$

$\begin{array}{ll}1.2 \text { History of tea plant } & 09\end{array}$

$\begin{array}{ll}\text { 1.3. Agriculture of tea } & 10\end{array}$

1.4. Manufacturing process of black tea. 11

$\begin{array}{ll}1.5 \text { Objectives of the study } & 13\end{array}$

Chapter 02

2. Literature review 14

2.1 Chemistry and Biochemistry of tea 14

2.2 Polephenols in tea 14

2.3 Composition of a typical tea beverage 16

2.4 Physiological effects of tea 16

$\begin{array}{ll}2.5 \text { Polephenols as antioxidants } & 16\end{array}$

$\begin{array}{ll}2.6 \text { Sri Lankan tea industry } & 17\end{array}$

2.7 Different regions and sub-districts where teas are grown

Chapter 03

3.1 Experimental / Methodology 20

3.2 Methodology used $\quad 22$

3.3 Measurement of sample 23

3.4 Preparation of standard solution series $\quad 24$

3.5 Calculation of tea polephenols 25

3.6 Calculation of the dilution of tea extracts 25

3.7 Relating tea extract absorption values with the standard series 26

4.0 Results and Discussion 26

4.1 Analyses and Interpretation of results $\quad 27$

4.2 Statistical analyses of results $\quad 34$

4.3 Significance of relationship between variables and predictors 42

5. Conclusion and Recommendations 43

References $\quad 44$

Appendices $\quad 45$ 


\section{ACKNOWLEDGEMENT}

I would wish to express my sincere gratitude to my external supervisor

Dr. K.K.D.S. Ranaweera, Co-ordinator of MSc. in Food Science \& Technology and Head Department of Food, for all the valuable guidelines and insights given to me in completing this project.

Also, I would wish to express my heart full thank to my internal supervisor Mr. Chaminda Munasinghe, for assisting and guiding me towards a successful completion of the project.

Special thank is extended to Dr. Tissa Amarakoon - Head of Biochemistry, Tea Research Institute, Sri Lanka, for his valuable contribution made, Mr. Mohan Lokuge and all the staff members at laboratory and Mr. Buddhi Somaweera in the Quality Assurance department Unilever Sri Lanka Ltd., who assisted me in numerous ways and means in completion of this report. 


\begin{abstract}
Tea in general is considered as a health beverage, although varying claims are still being made concerning the health benefits of tea.

Sri Lanka is the third largest exporter of tea, with the widest variety offered to international customers. Japan is a larger importer of Ceylon teas with a percentage share of 5.94, with a consumption of 130,000 metric tonnes to $2,188,000$ metric tonnes of black tea in total in 1993. Majority of its customers focus on the health benefits provided by same, claims that the levels of tannin content in Ceylon teas is having a declining trend with time since of late. They being the customer, are interested in understanding the probable cause(s) for same.
\end{abstract}

They are also concerned on how the Tannin content varies in regional specific Ceylon black tea and also in understanding the factors contributing to the said variation such as the Agro climatic conditions, soil conditions etc... Therefore, they proposed an analysis to be carried out in order to verify same. Certain concerns could be noted in this study, such as the differences in the methodologies adopted in analysing the tannin contents, which could most probably be the cause for varying results and also the analysis method below adopted by the Tea Research Institute has analysed for total polyphenols and catechines and the method adopted in this study has focussed only on tannins. However, owing to Unilever safety guidelines, the methanol extraction of tea could not be carried out. Hence, had to carryout only the hot water extraction method. 
Method used by the Tea Research Institute :- ISO method for total polyphenols - ISO 14502-1 (2005) is as follows:

Procedure :-

1. Tea sample has to be grinded.

2. Extraction into Methanol/water (70\%)

3. Folin-Ciocalteu reagent added.

4. Spectroscopic meaurement at $765 \mathrm{~nm}$.

5. Standard graph is prepared using gallic acid as standard.

Analysis results for Total polyphenols and individual catechins according to the said method.

\begin{tabular}{|l|c|c|}
\hline Region & $\begin{array}{c}\text { \% of Total } \\
\text { Polyphenols }\end{array}$ & $\begin{array}{l}\text { \% of Total catechins } \\
\text { Nuwara Eliya/ }\end{array}$ \\
Udapussellawa & 18.47 & 6.41 \\
\hline Western Region & 15.06 & 2.12 \\
\hline Uva & 13.82 & 1.9 \\
\hline Mid Country & 18.34 & 3.68 \\
\hline Low Country & 19.69 & 4.59 \\
\hline
\end{tabular}

Some interesting observations risen from the results could be seen in experiment carried out are as follows:-

- There is no direct co-relation of temperature to the variation in tannin content in any of the agro climatic subdivisions chosen for the study.

- There has been a positive co-relation with the rain fall in the 04 month period in two regions.

viz.:- Uva region and Nuwaraeliya / Udapussellawa region 
- There has been a negative co-relation with the rain fall in the 04 month period in the other three regions,

viz.:- Mid grown, Western region and Low grown region.

These are further discussed under 'RESULTS AND DISCUSION' below 


\section{CHAPTER 01}

\section{INTRODUCTION}

Tea is the most popular beverage in the world, second only to water. Tea (Camellia sinensis) (L). O. Kuntze is considered to be the most popular non alcoholic beverage next to water. What are plucked for processing are the tender leaves and the bud of the tea plant, which is referred to as the flush.

\section{What are Tea Tannins?}

Tannins are a group of very astringent compounds which bind themselves to protein. Tannins also combine with enzymes because these are proteins. The tanning of enzymes leads to inactivation or reduction of enzyme activity .

\subsection{HISTORY OF TEA}

Tea has been discovered by the Chinese emperor Shen Nung where he claimed that it was able to detoxify 72 kinds of poison (Teranishi et al., 1995)

Tea became very popular in both east and west and the present tradition of the afternoon tea established particularly as a British habit. Cultivation of tea was introduced to several other countries, with the growing popularity of tea.

\subsection{HISTORY OF TEA PLANT}

Tea plant was classified as Thea sinensis in 1753, in the binomial system originated by Linnaeus. Many synonyms have bee given, but now it is generally accepted that the tea plant is classified in the family Theaceae and in Camellia species.

Commercially cultivated tea consist of natural hybrids of 03 main types. VizCamellia sinensis var sinensis for small leaves China plants. 


\subsection{AGRICULTURE OF TEA}

Tea grows best in tropical and sub-tropical areas where adequate rain fall of approximately $2,000 \mathrm{~mm}$, good drainage and slightly acidic soils prevail. In hot tropical areas quality is improved by planting at higher altitudes as practiced in Sri Lanka, where tea cultivation is done at elevations upto 2,000 meters. 


\subsection{MANUFACTURING PROCESSOF BLACK TEA}

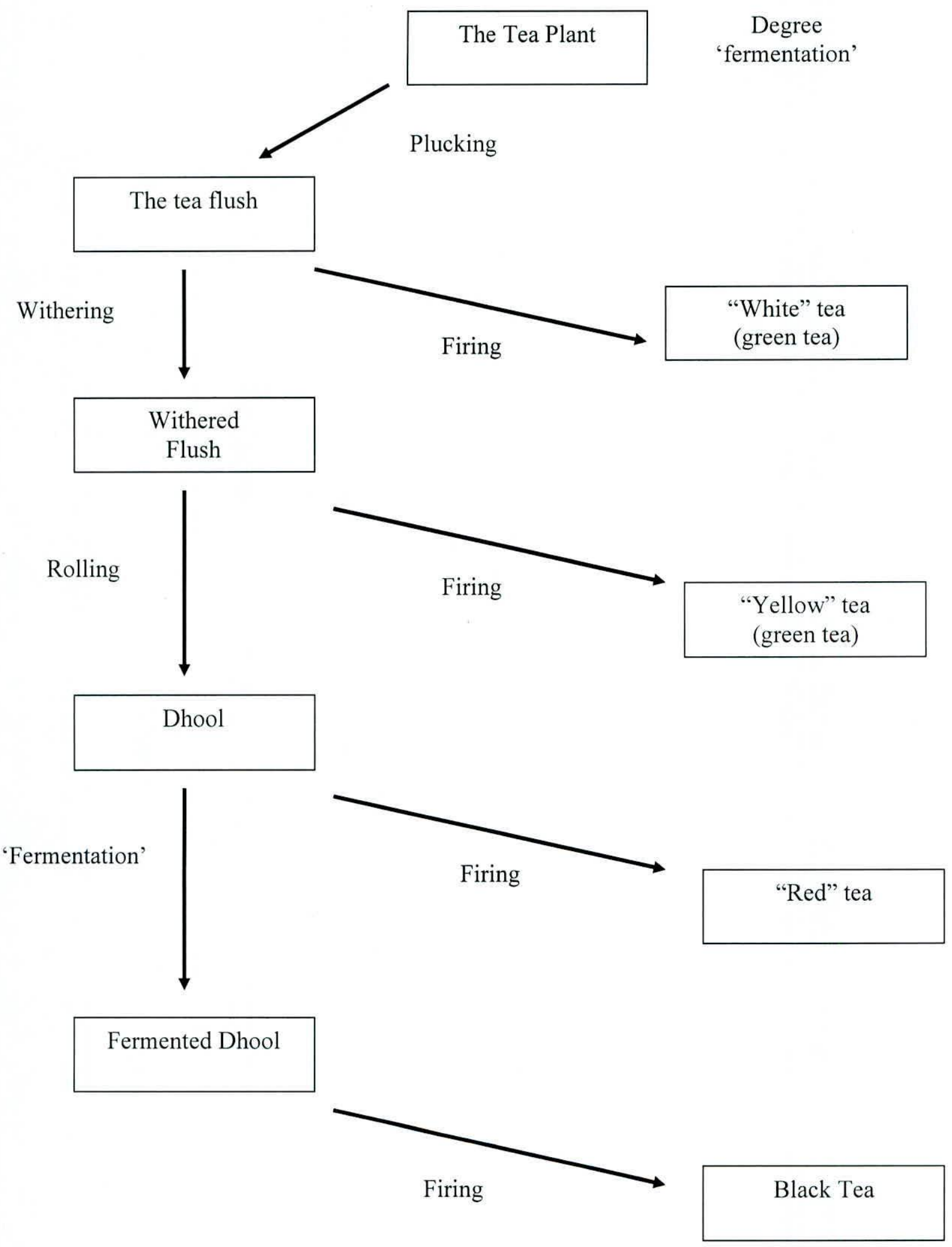


When oolong and black teas are to be produced, the fresh leaves are allowed to be produced, the fresh leaves are allowed to wither until the moisture content of the leaves is reduced to $55 \%$ to $72 \%$ of the leaf weight.

\subsubsection{Withering}

Harvested teas are handled in a manner to prevent bruising and to promote dissipation of heat generated during continued respiration. The moisture content of tea is reduced from $75 \%$ to $55 \%$ approximately, by a flow of cool air.

\subsubsection{Rolling}

Rolling helps to establish proper conditions for enzymatic oxidation of the flavanols, by atmospheric oxygen. Rolling is accomplished by disruption of the cell structure which facilitate enzyme - substrate contact. The leaf mass is also maintained in a physical state

\subsubsection{Fermentation (Oxidation)}

During this process the green leaf is converted to black tea. Although this is referred to as fermentation, it became recognised around 1901 as an oxidation process initiated by the tea enzymes. This process actually starts at the onset of maceration and it allowed continuing under ambient conditions. Temperature of the leaf is maintained around $25-30 \mathrm{C}$.

\subsubsection{Firing}

At this stage of processing, fermenting enzymes are deactivated by passing hot forced air over the tea leaves. Many organochemical processes are accelerated during this period, as are the enzymatic reactions before thermal inactivation. 
Firing also reduces the moisture level to $2 \%-3 \%$. This is critical as incomplete inactivation can cause accelerated deterioration during storage.

\subsubsection{Sorting}

The dried teas are sorted into different grades, by passing it over a series of vibrating screens of different mesh sizes. Electro statically charged rollers preferentially attract and remove fibre and stalks in the processed black tea.

\subsection{OBJECTIVES OF THE STUDY:}

- To study the variation of Tannin content in regional specific Ceylon black tea.

- To understand the factors contributing to the said variation such as the Agro climatic conditions, soil conditions etc...

- To recommend tea drinking consumer segments, the means of extracting the maximum tannin content to the brew, in order to obtain maximum possible health benefits. 


\section{CHAPTER 02}

\section{LITERATURE REVIEW}

\subsection{CHEMISTRY \& BIOCHEMISTR OF TEA}

Tea is the subject of many biochemical investigations as it produces a number of unique natural products. in contrast to the isolation and quantification of the Tea flush, consisting of the terminal bud and two adjacent leaves of the tea plant

Tea is rich in high amounts of anti oxidant flavonoids, which help clean harmful compounds from the blood.

\subsection{POLYPHENOLS IN TEA:}

The term polyphenol is an inclusive descriptor referring to the millions of natural and synthetic aromatic molecules that are substituted with multiple hydroxyl groups. Polyphenols of Black tea are poorly understood but seemingly well defined group of compounds. These are principally responsible for the colour and astringency and partially responsible for flavour. The most abundant class of chemical compounds in fresh tea flush is the polephenols. (made up of many phenol molecules) The phenol molecule has a single hydroxyl group attached to an aromatic ring; the polyphenols have a mumber of these $-\mathrm{OH}$ groprs. Of the polyphenolic categories, the flavonoids are the most abundant in tea flush. Flavonoids are 2- phenyl benzopyran based compounds, classified into six groups:

Flavones.

Flavanones.

Isoflavones.

Flavanols (including catechines or flavan - 3- ols)

Flavonols

Anthocyanidins

Flavanols and Flavonols are the main components in fresh leaf. Catechines are the major flavanols in tea. EGCG, EGC, ECG, EC,GC and C and they undergo oxidative dimerisationn or polymerisation during black tea manufacture. 
Flavonols (such as quercetin, kaempferol, myricetin and their glycosides) and anthocyanidins are also found in the flush in appreciable amounts, but they do not undergo much change during black tea manufacture The tea leaves contain two enzymes, plephenol oxidase and peroxidase, which are involved I the oxidation of polephenols.

These may be subdivided by several chemical backbone structures comprising of:-

\section{Simple tea polyphenols}

Gallic Acid and its quinic acid ester (or depside, as quinic acid esters are commonly referred), theogallin, have been identified in tea.

Other polyphenols Flavones and their glycosides such as Apigenin have been detected in tea but represent a very small fraction of the polypheenols present.

\subsubsection{Tannins:-}

Although it is commonly stated that there are no tannins (meaning Hydrolyzable tannins such as pentagalloylglucose ) in tea, this statement is not strictly true. In addition to the gallic acid esters of the catechins and their oxidation products (which can be hydrolyzed to produce gallic acid readily and precipitate proteins), there is also a small quantity of hydrolysable tannin (Nonaka et al., 1984; Yoshida et.al 1990; Hatano et.al., 1994.) The unique hydrolysable tannins in tea are typically "hybrid" tannins such as camelliatannin A, which is a galloylglucose derivative with pendant catechines. The tanic acid derivatives common to gall- nuts and tree bark are not present in significant quantities in tea infusions.

\subsubsection{Catechins:}

Of the total catechines consumed by humans, a large percentage passes out unchanged in the faeces (Hara, 1997) and of that absorbed into the body, approximately $60 \%$ are excreted in the urine and the rest in the bile (Brown 